Goldschmidt 2021 Abstract

https://doi.org/10.7185/gold2021.3961

\section{Origin of Soil Organic Carbon Persistence Revealed by Nanoscale Analyses}

MATHIEU CHASSÉ ${ }^{1}$, CORENTIN LE GUILLOU ${ }^{2}$, JEANCHRISTOPHE VIENNET ${ }^{3}$, SYLVAIN BERNARD ${ }^{4}$ AND PIERRE BARRÉ ${ }^{5}$

${ }^{1} \mathrm{CNRS}$ - IMPMC

${ }^{2} \mathrm{CNRS}$ - UMET

${ }^{3} \mathrm{IMPMC}$

${ }^{4}$ IMPMC CNRS/Sorbonne Université/MNHN

${ }^{5} \mathrm{CNRS}$ - Laboratoire de géologie de l'ENS

Presenting Author: mathieu.chasse@normalesup.org

Understanding the origin of long-term, i.e. pluri-decadal to centennial, soil organic carbon persistence is crucial to manage and forecast soil carbon stocks evolution, a key challenge to improve soil security and constrain soils influence on climate change. Persistence is expected to result either from (1) chemical recalcitrance (i.e. specific chemical structure reducing the rate of decomposition), (2) physical or physico-chemical protection (i.e. material or energetic barrier induced by organo-mineral interactions preventing decomposition). The nature and relative importance of these processes remain elusive due to the nanometric scale of the protection and the difficulty to separate persistent organic carbon from ordinary one.

We overcome these limitations by combining scanning transmission X-ray microscopy (STXM) and scanning transmission electron microscopy (STEM) to study soil samples from the oldest long-term bare fallow field experiment. In these field experiments, conducted on a silt-loam luvisol under temperate climate, carbon inputs to the soil were stopped eighty years ago. A fraction of the organic carbon was gradually decomposed resulting in an enrichment in persistent organic carbon. The comparison of the properties of organic carbon in soil after eighty years with organic carbon sampled at the onset of the experiment can help elucidating the mechanisms leading to its persistence. The spatial resolution of the analytical techniques gives access to textural and chemical properties at the nanometric scale at which protection mechanisms are expected to occur.

The analysis of STXM-near-edge X-ray absorption fine structure spectra gives access to carbon speciation at a $100 \mathrm{~nm}$ resolution. Carbon-rich particles above this size are scarce in the samples rich in persistent organic carbon, dominated by a diffuse carbon signal. This organic carbon exhibits a molecular composition similar to that of average soil organic carbon. Chemical recalcitrance is thus secondary in explaining persistence in contrast to physico-chemical interactions occurring below $100 \mathrm{~nm}$. At such scales, STEM images (Figure 1) coupled with energy dispersive spectroscopy (Figure 2) indicate that this diffuse carbon is mixed with or adsorbed on phases which size is often below a few dozens of nanometers. Physico-chemical interactions with such nanophases must then explain soil organic carbon persistence.
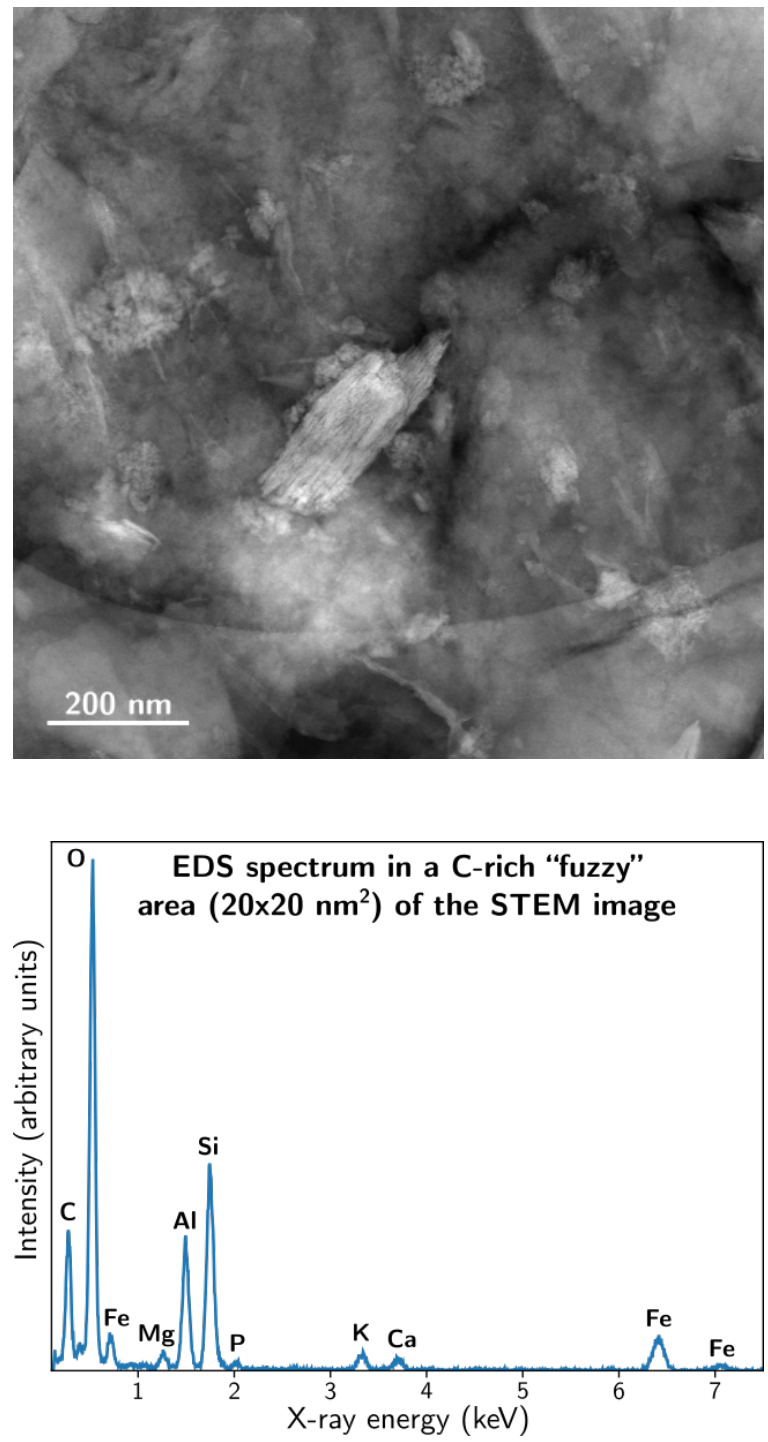